\title{
PAUL RICOEUR E O DESAFIO ATUAL DOS DIREITOS HUMANOS
}

\author{
PAUL RICOEUR AND THE CURRENT CHALLENGE OF HUMAN RIGHTS
}

Thiago Sousa*

\section{RESUMO}

Trata-se, no presente texto, de uma aula ministrada no curso para diversas graduações, como direito, psicologia, geografia, etc. de Introdução à Filosofia: Ética, na Universidade Federal de Minas Gerais (UFMG), como cumprimento do estágio docente do doutorado em Filosofia, sob a supervisão do Prof. Dr. Tadeu Mazzola Verza. Sendo assim, nosso objetivo era duplo: apresentar uma introdução filosófica acerca de questões éticas e, ao mesmo tempo, introduzir nossos estudantes ao estilo filosófico ricoeuriano. Para alcançarmos isso, escolhemos a temática da Declaração Universal dos Direitos Humanos e como esta era vista pelo senso comum dos brasileiros. A partir dos dados obtidos, por meio de uma investigação estatística, exploramos, usando alguns recursos didáticos, como tirinhas, as fronteiras e relações que existem para Paul Ricoeur entre as fontes não filosóficas e a elaboração própria de um ponto de partida para filosofia. Por fim, convidamos os estudantes, ao citar um trecho de $O \mathrm{si}$ mesmo como outro, a formular uma questão filosófica que serve como guia para uma investigação acerca das formulações éticas presentes na obra ricoeuriana, a saber, qual a necessidade de se pensar em Direitos Humanos filosoficamente na contemporaneidade, que se estende até os dias atuais?

PALAVRAS-CHAVE: Paul Ricoeur. Direitos Humanos. Ética.

\begin{abstract}
The following paper is from a class taught to undergraduate students from several courses, such as law, psychology, geography, etc. of Introduction to Philosophy: Ethics, at the Federal University of Minas Gerais (UFMG), as a fulfillment of the teaching internship of the Ph.D. in Philosophy, under the supervision of Prof. Dr. Tadeu Mazzola Verza. Consequently our objective was dual: to present a philosophical introduction about ethical issues and, at the same time, to introduce our students to the Ricoeurian philosophical style. To achieve this, we choose to use the Universal Declaration of Human Rights and how it's perceived by Brazilians, as a theme. From the data obtained, through a statistical investigation, using some didactic resources such as comic strips, we explored the boundaries and relationships that exist for Paul Ricoeur between non-philosophical sources and the proper elaboration of a starting point for philosophy. Conclusively, we invited our students, citing excerpts from Oneself as Another, to formulate a formal philosophical question that serves as a guide for an investigation into ethical formulations present in the richeurian work, namely, what is it that makes it necessary to think about Human rights philosophically in contemporary times, which extends to the present day?
\end{abstract}

KEYWORDS: Paul Ricoeur. Human Rights. Ethics.

\footnotetext{
*Doutorando em filosofia pela UFMG. E-mail: thiago-luiz-sousa@hotmail.com.
} 
Como nos mostra Henrique Cláudio de Lima Vaz, em seu artigo Metafísica e fé cristã: uma leitura de "Fides et Ratio", podemos sempre considerar os problemas filosóficos por dois ângulos: (a) por meio de uma atualidade permanente; (b) por meio de uma atualidade conjuntural (VAZ, 1999, p. 294). Vaz faz essa distinção para apresentar o lugar que ocuparia a problemática do livro lançado pelo papa João Paulo II, que nesse caso seria uma atualidade conjuntural, na história da filosofia, que seria uma atualidade permanente. $\mathrm{O}$ importante a ser notado é a relação que se estabelece entre o pensamento atual e o pensamento histórico, entre a problemática filosófica atual e a problemática filosófica histórica. Com isso, podemos apresentar a seguinte questão: que relação o pensamento atual dos direitos humanos apresenta quando pensamos em uma história filosófica dos direitos humanos?

Com essa questão, estabelecemos a problemática de nosso curso. Nesse sentido, nosso objetivo não é apenas compreender o pensamento ricoeuriano sobre ética, mas questionar o quanto o pensamento ricoeuriano sobre ética pode contribuir na resposta de nossa problemática. Mas isso não é complicar as coisas? No caso de Ricoeur, cremos que não, pois sua própria filosofia foi feita nesses moldes. Em A crítica e convicção, ele afirma: “[...] gosto muito da ideia de que a filosofia se dirige a determinados problemas, a embaraços de pensamento muito delimitados" (RICOEUR, 1995, p. 115). Curiosamente, até mesmo na obra em que ele diz que "[...] moveu-[se] contra a correnteza em relação às [suas] preferências consolidadas [...]" (2011, p. 128-129), encontramos questões delimitadas, isto é, em vez de apresentar para nós apenas uma questão delimitada, como em suas outras obras, ele nos apresentou quatro questões delimitadas ${ }^{1}$. Dito isso, podemos retornar à nossa questão, ou melhor, podemos delimitá-la ainda mais, dividindo-a em três questões menores, a saber:

1. Qual é o pensamento atual de direitos humanos?

2. O que seria uma história filosófica dos direitos humanos?

3. Qual seria a relação entre o pensamento atual e essa história?

Para respondermos a primeira questão, recorramos a uma pesquisa recente sobre o tema. Segundo uma pesquisa, publicada no dia 16 de maio de 2018 , feita pelo Instituto Ipso e obtida pela BBC Brasil, dois em cada três brasileiros acreditam que os direitos humanos defendem mais os criminosos do que suas vítimas. Observemos o gráfico apresentado em tal reportagem:

\footnotetext{
1 A obra à qual estamos nos referindo é $O$ si-mesmo como outro e as quatro questões são as seguintes: "Quem fala? Quem age? Quem se narra? Quem é o sujeito moral de imputação?” (RICOEUR, 2014, p. XXXI).
} 
Gráfico 1 - Direitos humanos e percepção de Justiça ${ }^{2}$

Direitos Humanos e percepção de justiça

Eu vou ler algumas frases e gostaria que o Sr.(a) me dissesse qual delas mais se aproxima da sua opiniäo.

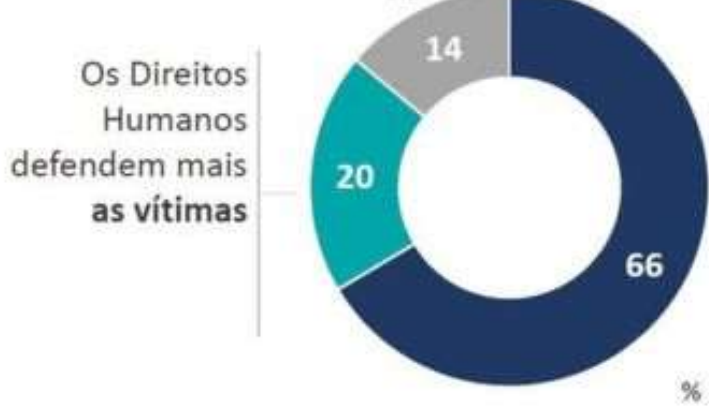

Os Direitos

Humanos

defendem mais

os bandidos

Ipsos Public Affairs

Fonte: IPSOS, 2018.

Após obter este resultado, a pesquisa foi além, questionando quais, então, seriam os mais beneficiados e menos beneficiados pelos direitos humanos, obtendo este novo gráfico:

Gráfico 2 - Beneficiados e prejudicados com os Direitos Humanos ${ }^{3}$

\section{Beneficiados e prejudicados com os Direitos Humanos}

No Brasil, quem mais se beneficia com a atuação dos Direitos Humanos? / E quem menos se beneficia com a atuaçẵo dos Direitos Humanos?

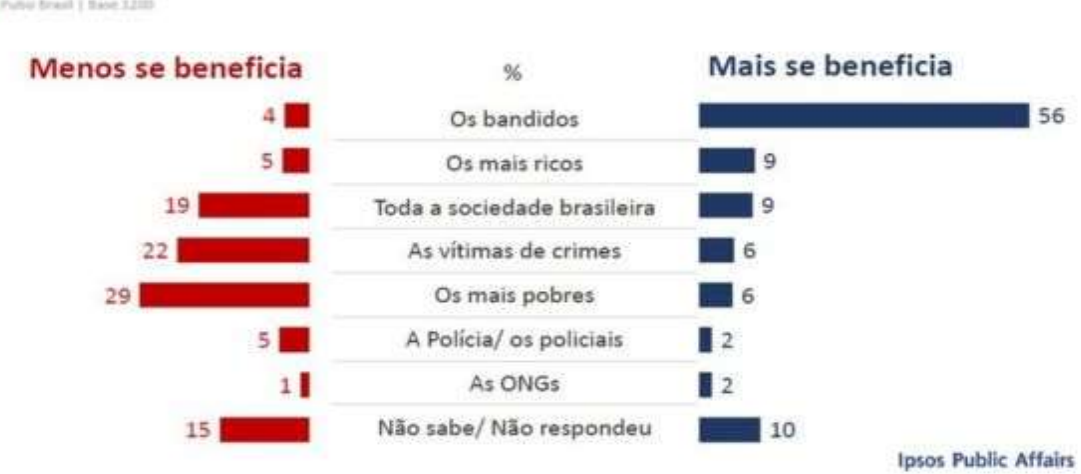

Fonte: IPSOS, 2018.

Gostaríamos de destacar a terceira linha do gráfico, que aponta que 19\% acreditam que toda sociedade brasileira é que menos se beneficia dos direitos humanos, enquanto apenas $9 \%$

2 Gráfico disponível em https://www.bbc.com/portuguese/brasil-44148576

${ }^{3}$ Gráfico também disponível em https://www.bbc.com/portuguese/brasil-44148576 
acredita que ela é a que mais se beneficia. Com isso, não é surpresa quando vemos a seguinte afirmação na reportagem: “[...] 54\% concordam com a afirmação de que 'os direitos humanos não defendem pessoas como eu"” (SHALDERS, 2018).

Devemos observar dois pontos na construção de nossa problemática: (i) o uso de uma não filosofia; (ii) o estatuto filosófico de nossa questão. Ao elaborarmos nossa questão, não recorremos a uma pesquisa filosófica, mas, sim, a uma pesquisa estatística. Com isso, nos aproximamos novamente do pensamento filosófico de Ricoeur, pois em Filosofar após Kierkegaard, encontramos a seguinte afirmação do filósofo francês:

\begin{abstract}
A filosofia sempre tem a ver com a não-filosofia, porque a filosofia não tem objeto próprio. Ela reflete sobre a experiência, sobre toda experiência, sobre o todo da experiência: científica, ética, estética, religiosa. A filosofia tem suas fontes fora de si mesma. Digo suas fontes, não seu ponto de partida; a filosofia é responsável pelo seu ponto de partida, por seu método, por seu acabamento; a filosofia busca seu ponto de partida; ela vai para o seu ponto de partida; sobre isso, Pierre Thévenaz, nosso querido e sempre pranteado Thévenaz, disse coisas convincentes e decisivas: a filosofia tem seu ponto de partida diante dela. Mas, se ela busca seu ponto de partida, ela recebe suas fontes; ela dispõe do seu ponto de partida, não dispõe de suas fontes, vale dizer, do que revitaliza e instrui pela base. É assim que compreendo a frase de Karl Jaspers: "Nós que não somos a exceção, devemos filosofar com o olhar fixo na exceção". (RICOEUR, 1996, p. 34, grifos nossos).
\end{abstract}

$\mathrm{Na}$ citação acima vemos uma distinção sutil, mas fundamental, entre as fontes filosóficas e o ponto de partida filosófico. Paul Ricoeur defende que as fontes filosóficas vêm das não filosofias, isto é, o que faz a filosofia iniciar sua reflexão é outra ciência, que não ela mesma. Se pensarmos nos filósofos do passado, veremos que não é um absurdo a afirmação ricoeuriana. Em uma entrevista, ele esclarece de outro modo esse mesmo ponto, quando afirma: "Todos os grandes filósofos do passado foram competentes numa ciência e muitas vezes em várias: Platão era geômetra, Descartes, matemático, etc. Por conseguinte, a filosofia não se limitava a um debate consigo mesma” (RICOEUR, 1976, p. 2). Ora, é esse encontro tão comum nos filósofos do passado que, segundo Ricoeur, é responsável pela renovação da filosofia. Por isso, ao comentar o pensamento ricoeuriano, Eduardo Gross (2015, p. 5) destaca: "Não existe objeto alheio ao interesse da filosofia". No entanto, esse objeto, essa fonte não é o ponto de partida da filosofia. O ponto de partida da filosofia está na exceção. Mas, quem é a exceção? A exceção é o filósofo. Para compreendermos melhor esse ponto, vejamos o que Ricoeur afirma acerca do ser filósofo em História e verdade:

O grande filósofo é aquele que pela primeira vez se espantou com uma maneira nova de filosofar - uma questão que é um alguém; nele a razão filosófica é antes de tudo a elaboração sob forma universal de sua questão fundamental: problema cartesiano da 
certeza, problema kantiano dos julgamentos sintáticos a priori. Se se aborda uma filosofia nova mais por suas perguntas do que por suas respostas, tem-se possibilidade de marchar em direção àquele centro em que se reúnem as influências; as filosofias não mais são ali causas objetivas, mas aspectos de sua situação fundamental, aspectos de uma "motivação filosófica" - de um Umwelt totalmente motivante; uma filosofia não é mais o efeito de um conjunto de causas, mas antes a aglomeração, e até certo ponto a eleição de seus próprios motivos históricos. (RICOEUR, 1968, p. 52).

Diante disso, podemos afirmar: o filósofo é a exceção, pois ele encontra nele mesmo uma maneira original de formular uma questão universal. Então, o ponto de partida do grande filósofo é ele mesmo. Por exemplo, por que Sócrates é um grande filósofo? Porque ele encontrou, nele mesmo, uma maneira nova de questionar, no caso, uma maneira de tentar dar explicação para algumas questões sem recorrer aos mitos. Creio que esta tirinha ilustra muito bem tal situação:

Figura 1- Tirinha Sócrates ${ }^{4}$.
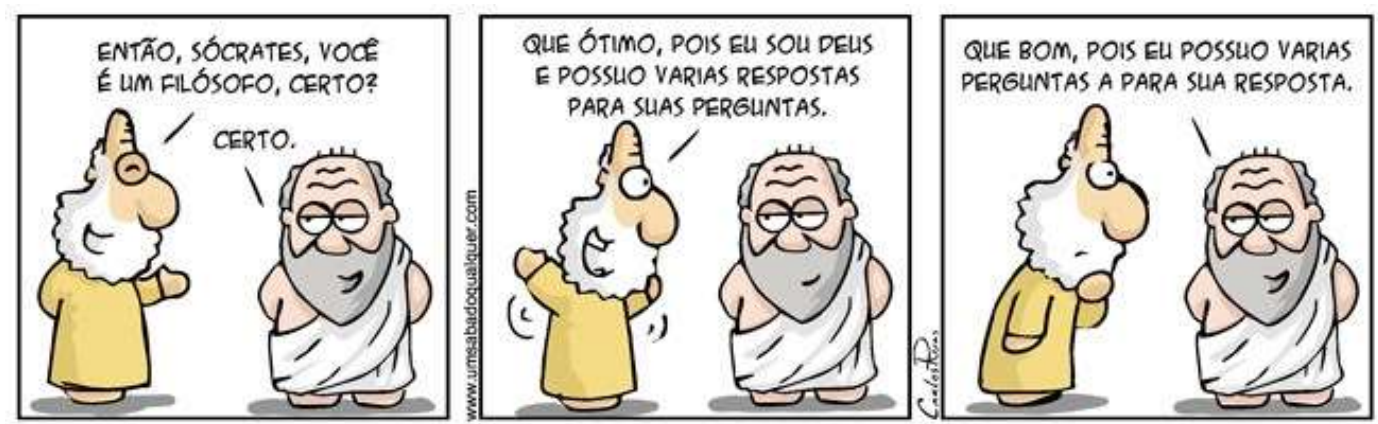

Fonte: RUAS, 2012.

Mas, por que estamos falando de grande filósofo? Pois existem os "grandes" filósofos, como Sócrates, e existem os pequenos filósofos, como eu e você, que para fazer filosofia não partimos de nós mesmos, mas partimos de um filósofo. Aparece aqui o papel importante que tem a história da filosofia. A história da filosofia é importante para nós, porque ela nos permite fazer filosofia nos dias de hoje, sem que tenhamos uma genialidade imensa. Por outro lado, caso tenhamos tal genialidade, ela também se faz importante, uma vez que só saberemos se somos geniais de fato, se defrontarmos nosso pensamento com o de outro grande filósofo. Por isso, Ricoeur afirma: “[...] o mais autodidata dos filósofos não se pode furtar a Sócrates, Platão, Descartes, Kant: a história deve ter sentido para a própria pesquisa da verdade" (RICOEUR, 1968, p. 45). Nota-se que este esquema vai além da famosa distinção entre

\footnotetext{
${ }^{4}$ Tirinha disponível em: https://www.umsabadoqualquer.com/857-socrates-16/
} 
filósofo e comentador de filosofia, uma vez que o comentador seria aquele que deixou de usar a não filosofia como fonte e vai em direção à história da filosofia apenas para descrevê-la, isto é, não vai em direção à história da filosofia em busca de novas respostas. Não é sem razão que Michel Philibert afirma:

\begin{abstract}
O traço que torna Paul Ricoeur único em nosso tempo e não menos na história da filosofia, está no modo como ele combina uma ardente e humilde atenção em relação a praticamente todos os filósofos anteriores com uma simpatia por nossa situação presente e uma modesta, mas forte determinação de falar de si mesmo sobre qualquer problema com o qual lida. (PHILIBERT apud ALMEIDA, 1992, p. 67).
\end{abstract}

Talvez esteja aqui a causa da grande dificuldade que temos ao ler a obra ricoeuriana. Paul Ricoeur é uma "exceção", mas escreve como se não fosse uma. Ou seja, Paul Ricoeur é um grande filósofo, mas escreve como se fosse pequeno. Em seus textos há uma originalidade própria, porém, como ele mesmo admite, às vezes, essa originalidade aparece apenas nas últimas páginas de sua obra, após um longo debate com a história da filosofia, como é o caso da obra Tempo e narrativa, em que encontramos a noção de identidade narrativa apenas nas últimas páginas. Mas por que isso acontece?

Seus primeiros leitores eram seus alunos (RICOEUR, 1995, p. 43), isto é, um dos aspectos de seus escritos é ser de instrução. Como nota Jean Grondin (1998, p. 11), Ricoeur até lamenta tal didatismo. Em $A$ crítica e convicção, ele nos fala que em sua obra "[...] a forma pedagógica permanece demasiadamente presente" (RICOEUR, 1995, p. 73). No entanto, nesse mesmo livro, o filósofo francês nos diz que apesar de ele rejeitar um sistema totalizante, essa busca didática fez com que sua obra tivesse certa sistematicidade (p. 43). O ponto que queremos mostrar com isso é que, independentemente de excesso de didatismo ou não, Ricoeur não faz apenas seu filosofar, mas de seu ensino de filosofia uma espécie de aventura filosófica. Ou seja, mais do que aprender história da filosofia, a obra ricoeuriana convida-nos a nos "aventurar", ou melhor, a filosofar. Dito isso, voltemos à nossa própria aventura. Mas será que não é esta postura que todo filósofo grande deveria buscar? $\mathrm{Ou}$ melhor, mais do que ser um "guru", o grande filósofo não deve mostrar como encontrou ou defrontou seus próprios "gurus"? Assim afirma Filipe Campello:

Quem se coloca, arrogantemente, numa posição de guru, age contra o próprio
exercício filosófico. Fazer filosofia, boa ou má, é primeiramente tornar-se
independente de gurus. Pensar por si mesmo é uma tarefa árdua e que pode colocar
em questão até mesmo aquilo em que acreditamos. Mas esse é o fascínio de se fazer
filosofia. Assumir essa postura não é uma batalha entre esquerda e direita, menos
ainda entre marxismo cultural e conservadorismo; é uma batalha contra o
obscurantismo, contra a ridicularização das próprias premissas da reflexão filosófica. 
Qualquer um que seja contra tal retrocesso civilizatório deveria estar na linha de frente dessa batalha. (CAMPELLO, 2019).

Após este breve desvio comentando o modo de filosofar ricoeuriano, cremos que conseguimos justificar o uso de uma não filosofia em nossa empreitada filosófica, ponto (i) que devíamos esclarecer. Os dados da pesquisa estatística servem de fonte para nossa pesquisa, mas não como ponto de partida. Nossa fonte nos mostrou, entre outras coisas, duas situações: (a) 66\% dos entrevistados acreditam que os direitos humanos defendem bandidos; (b) $54 \%$ dos entrevistados creem que os direitos humanos não defendem pessoas como eles. Esses pontos não filosóficos se transformam em uma questão filosófica no momento em que os confrontamos com um ponto de partida filosófico, isto é, quando tentamos pensá-los, por exemplo, diante desta afirmação de Ricoeur, que encontramos na elaboração de sua ética:

\footnotetext{
Um exemplo de tal dialética [entre universalismo e contextualismo] é dado pela atual discussão em torno dos direitos humanos. No essencial, estes, tomados no nível de textos declarativos, e não propriamente legislativos, podem ser considerados derivados bem argumentados da própria ética da argumentação. Além disso, foram ratificados quase pela unanimidade dos Estados; no entanto, permanece a suspeita de que são apenas fruto da história cultural do Ocidente, com suas guerras de religião, seu aprendizado laborioso e nunca terminado de tolerância. É como se o universalismo e o contextualismo se sobrepusessem imperfeitamente em torno de valores pouco numerosos, mas fundamentais, tais como o que se leem na Declaração Universal dos Direitos do Homem e do Cidadão. (RICOEUR, 2014, p. 337-338, grifos nossos).
}

Como podemos notar, segundo Ricoeur, os direitos humanos aparecem como uma sobreposição imperfeita entre universalismo e contextualismo. Os direitos humanos aparecem como um exemplo de uma ética que deve ao mesmo tempo, mesmo que de maneira imperfeita, pensar no contexto, no singular, e no universal. Com isso, podemos elaborar nossa questão filosófica: dada a imperfeição do nexo entre universalismo e contextualismo, ao ponto de mais da metade dos entrevistados não acreditar estar inserida no universal dos direitos humanos, por que uma ética é necessária? Por que devemos pensar em direitos universais? Será que com essa conciliação, como $66 \%$ dos entrevistados acreditam, não estamos defendendo bandidos?

Diante disso, podemos tentar responder as questões que apresentamos no início de nosso itinerário: 
1) Qual é o pensamento atual de direitos humanos?

R: Segundo uma pesquisa estatística, o pensamento atual dos direitos humanos é de que a maior parte dos brasileiros não se sente inserida neles e acredita que eles estão a favor de bandidos.

2) O que seria uma história filosófica dos direitos humanos?

R: Segundo Ricoeur, os direitos humanos estão inseridos na história da ética, no momento da conciliação entre uma ética universalista e uma ética contextualista.

3) Qual seria a relação entre o pensamento atual e a história?

R: O pensamento atual aponta para uma investigação acerca da necessidade dessa conciliação.

Como podemos ver, essas respostas nos conduzem para uma nova questão, que nos servirá de guia: qual a necessidade dos direitos humanos em uma ética filosófica?

\section{REFERÊNCIAS}

ALMEIDA, Danilo de. Consciência de si em Paul Ricoeur: consciência de si e o sentido da ação. 1992. Dissertação (Mestrado em Ciências da Religião). Programa de Pós-Graduação Instituto Metodista de Ensino Superior, São Bernardo do Campo, 1992.

CAMPELLO, Filipe. O antifilósofo: quem se coloca como guru age contra o próprio exercício filosófico. Folha de São Paulo, 2019. Disponível em:

https://www1.folha.uol.com.br/opiniao/2019/04/o-

antifilosofo.shtml?fbclid=IwAR2xkCRgEmoIhCupksyK3n-

T10Rx6s5TXF786DXObglzYh9gc9LSkIpxs14. Acesso em: 17 abr. 2019.

GRONDIN, Jean. Introdução à hermenêutica filosófica. Tradução Brenno Dischinger. São Leopoldo: Editora Unisinos, 1998. 336 p. (Focus; 2).

GROSS, Eduardo. A espiritualidade bíblica e a hermenêutica de Paul Ricoeur. Observatório da religião, Belém, v. 2, n. 2, p. 4-21, jan-jun, 2015.

RICOEUR, Paul. A crítica e a convicção. Tradução António Hall. Lisboa: Edições 70, 1995. (Biblioteca de filosofia contemporânea).

RICOEUR, Paul. Historia e verdade. Rio de Janeiro: Forense, 1968.

RICOEUR, Paul. Entrevista com Paul Ricoeur [sobre a crise da filosofia]. La philosophie d'aujourd'hui, Lausanne-Barcelone. Éditions Grammont-Salvat Editores (Bibliothèque Laffont des grandes thèmes), 1976. Tradução da Universidade de Coimbra. Disponível em: http://www.uc.pt/fluc/uidief/textos_ricoeur/filosofia actual. Acesso em: 15 dez. 2018. 
RICOEUR, Paul. Leituras 2: a região dos filósofos. Tradução Marcelo Perini e Nicolás Nymi Campanário. São Paulo: Loyola, 1996.

RICOEUR, Paul. O meu caminho para filosofia. In: JERVOLINO, Domenico. Introdução a Ricoeur. Tradução José Bertolini. São Paulo: Paulus, 2011, p. 120-143. (Coleção Filosofia em questão).

RICOEUR, Paul. O si-mesmo como outro. Tradução Ivone C. Benedetti. São Paulo: WMF Martins Fontes, 2014.

RUAS, Carlos. 857 Sócrates 6. Um sábado qualquer. 2012. Disponível em:

https://www.umsabadoqualquer.com/857-socrates-6/. Acesso em: 15 abr. 2019.

SHALDERS, André. Dois em cada três brasileiros acham que 'direitos humanos defendem mais os bandidos', diz pesquisa. BBC News Brasil, 2018. Disponível em: https://www.bbc.com/portuguese/brasil-44148576. Acesso em: 15 abr. 2019.

VAZ, Henrique C. L. Metafísica e fé cristã: uma leitura da "Fides et ratio". Síntese: revista de filosofia, Belo Horizonte, v. 26, n. 86, p. 293-305, 1999. 